\title{
OPEN Colloidal stability of phytosynthesised gold nanoparticles and their catalytic effects for nerve agent degradation
}

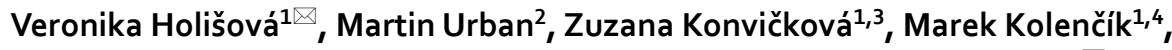 \\ Pavel Mančík ${ }^{1}$, Jiři Slabotinský ${ }^{2}$, Gabriela Kratošová ${ }^{1}$ \& Daniela Plachá1, ${ }^{1} \bowtie$
}

Herein, Tilia sp. bract leachate was used as the reducing agent for Au nanoparticles (Au NPs) phytosynthesis. The colloidal properties of the prepared Au NPs were determined to confirm their stability over time, and the NPs were then used as active catalysts in soman nerve agent degradation. The Au NPs characterisation, reproducibility and stability studies were performed under transmission electron microscopy, ultraviolet visible spectroscopy and with $\zeta$-potential measurements. The reaction kinetics was detected by gas chromatography coupled with mass spectrometry detector and solid-phase micro-extraction to confirm the Au NPs applicability in soman hydrolysis. The 'green' phytosynthetic formation of colloidal crystalline Au NPs with dominant quasi-spherical shape and $55 \pm 10 \mathrm{~nm}$ diameter was successfully achieved, and there were no significant differences in morphology, $\zeta$-potential or absorbance values observed during the 5 -week period. This verified the prepared colloids' long-term stability. The soman nerve agent was degraded to non-toxic substances within $24 \mathrm{~h}$, with $0.2156 \mathrm{~h}^{-1}$ reaction rate constant. These results confirmed bio-nanotechnology's great potential in preparation of stable and functional nanocatalysts for degradation of hazardous substances, including chemical warfare agents.

Chemical warfare agent (CWA) decontamination has a very high priority in military defence and especially in the current fight against terrorism. The Soman (O-Pinacolyl methyl-phosphonofluoridate) examined in this article is a CWA with extreme toxicity for biota. This organophosphate is a nerve agent (NA) which compromises the normal nervous system functioning by inhibiting acetylcholinesterase catalytic breakdown of acetylcholine and other choline ester neurotransmitters ${ }^{1,2}$. Soman causes death within a few minutes to a few hours after exposure, dependent on the dose and route of exposure, but it can be degraded by hydrolytic cleavage of its $\mathrm{P}-\mathrm{F}$ bonding ${ }^{1}$. Some toxicology studies show that pinacolylmethylphosphonic acid (PMPA) is formed as an intermediate substrate and that the methylphosphonic acid (MPA) usually formed as a final degradation product of soman hydrolysis is considered non-toxic ${ }^{2}$. Several studies have also focused on the degradation of CWAs and their simulants using different kinds of NPs. The Fe, $\mathrm{Zn}$ and $\mathrm{Al}$ metal nano-dispersed oxides or oxo-hydroxides have been prepared by homogeneous hydrolysis of sulphates, nitrates and chlorides and tested for their ability to convert nerve-agents to non-toxic products at $25^{\circ} \mathrm{C}^{3}$.

Chemical preparation of $\mathrm{Au}$ NPs supported on mesoporous $\mathrm{TiO}_{2}$ achieved effective soman photocatalytic decontamination ${ }^{4}$. The nanocomposite was prepared by biosynthesis using the Mallomonas kalinae brown algae with $\mathrm{SiO}_{2}$ on its surface, and soman degradation was confirmed by the nanogold embedded on this surface. Nanogold is a well-known catalytic nanomaterial, and Au NPs exhibit the thermodynamic stability, inertness, electric and optic conductivity applicable in a wide variety of catalysis. Au NP's catalysis is generally possible because of their large area and decreasing particle size distribution ${ }^{6-8}$, and the catalytic effect is significantly enhanced at higher nanogold crystallinity, by certain morphology types and uncovered grain boundaries. In addition, collective oscillation of conductive electrons between the dielectric and metal-surface plasmon resonance (SPR) occurs under an external optical field ${ }^{6,7}$, and the combination of these characteristics can lead to

\footnotetext{
${ }^{1}$ Nanotechnology Centre, CEET, VŠB - Technical University of Ostrava, 17. listopadu 2172/15, 70800 Ostrava, Czech Republic. ${ }^{2}$ National Institute for Nuclear, Biological and Chemical Protection, v.v.i., Kamenná 71, 262 31 Milín, Czech Republic. ${ }^{3}$ ENET Centre, CEET, VŠB - Technical University of Ostrava, 17. listopadu 2172/15, 708 00 Ostrava, Czech Republic. 'Department of Soil Science and Geology, Slovak University of Agriculture in Nitra, Tr. A. Hlinku 2, 94976 Nitra, Slovak Republic. ${ }^{\circledR}$ email: holisovaveronika@seznam.cz; daniela.placha@vsb.cz
} 

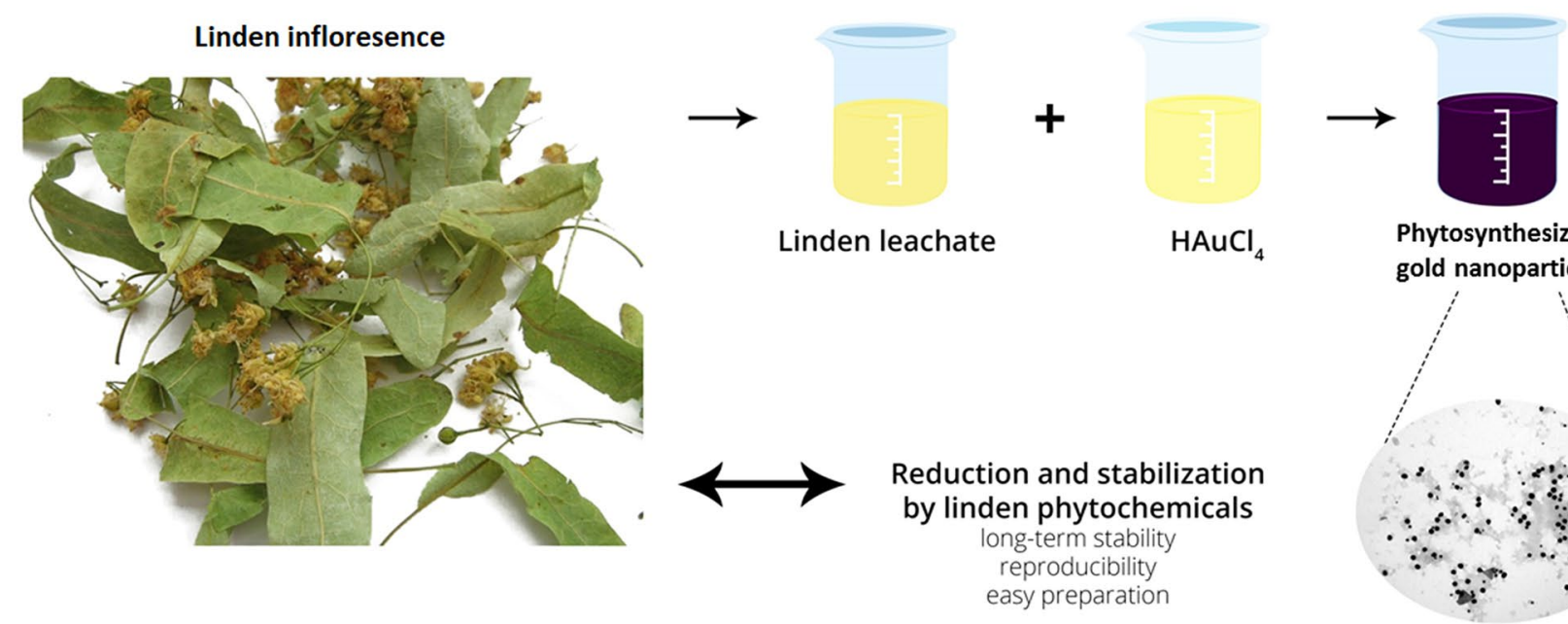

Phytosynthesized gold nanoparticles

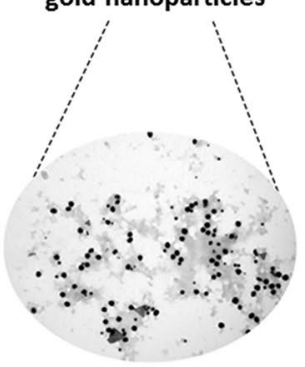

Au NPs

Figure 1. Batch phytosynthesis of Au NPs using linden bracts leachate.

the disruption of active bonds and groups of atoms in the organophosphate molecule ${ }^{9}$. Most importantly, Au NPs have no discernible toxic effects on living organisms ${ }^{10}$.

NPs can be prepared by biosynthesis as well as chemical and physical methods, and this provides an ecological approach of bottom-up synthesis ${ }^{11}$ where inorganic cores with functional organic packaging are formed. Relatively long-term stability and variability over a wide application range have recently proved surprising ${ }^{11}$, and Au NP biosynthesis has been confirmed in bacteria ${ }^{12}$, cyanobacteria ${ }^{13}$, algae ${ }^{8}$, microscopic fungi ${ }^{14}$ and different plant extracts ${ }^{15-17}$. The current use of plants or plant parts leachates and/or extracts for NPs biosynthesis is simple and attractive. This phytosynthetic method uses soluble plant substances such as alkaloids or simple phenolic compounds which possess both reduction and stabilisation effects ${ }^{17,18}$.

NPs stability is one of the most important properties in nanomaterial application ${ }^{15,16,19}$, and this is based on: (i) NP size, surface to volume ratio, crystallinity and morphology ${ }^{20}$; (ii) NP exposed surface charged with specific ions and an electric double-layer structure with specific capacity ${ }^{21}$ and (iii) the ionic strength and $\mathrm{pH}$, and other critical factors including temperature ${ }^{21}$.

Nanogold's remarkable properties make it one of the most catalytically active elements. Stable biosynthesised spherical Au NPs anchored on a silica surface have been employed in CO conversion ${ }^{8}$, and phytosynthesised nanogold was used for nitrophenol and organic dye degradation in the presence of $\mathrm{NaBH}_{4}{ }^{11,19}$. These effects inspired us to conduct the Au NPs phytosynthesis with Tilia sp. linden bract aqueous leachate in order to verify the NPs stability and experiment reproducibility. Finally, the Au NPs were used for soman degradation with subsequent evaluation by gas chromatography coupled with mass spectrometry and solid-phase micro-extraction.

\section{Results and discussion}

UV-VIS measurement. Suspension colour change from yellow to dark purple was observed after mixing the Au precursor and plant leachate for $15 \mathrm{~min}$ (Fig. 1). The nanogold batch phytosynthesis in all Au1-Au5 samples indicates the linden bracts leachate reducing potential, where the $\mathrm{Au}(\mathrm{III})$ ions are reduced to $\mathrm{Au}^{0}$ by phytochemicals present in the leachate ${ }^{11}$. Studies suggest that biomolecules such as proteins, enzymes and flavonoids can reduce $\mathrm{Au}(\mathrm{III})$ ions during phytosynthesis to form $\mathrm{Au}$ NPs and stabilise them directly in a one-step process $^{22,23}$

The Au samples' absorption spectra were measured in the 490 to $600 \mathrm{~nm}$ range and the characteristic absorption peaks were regularly determined over 5 weeks. The linden leachate and Au precursor mixtures exhibited one absorbance peak at 540-548 $\mathrm{nm}$ in the Au1-Au5 samples. This identified the Au NPs' SPR phenomenon ${ }^{24}$. Figure 2 depicts the Aul sample which was selected for soman degradation testing as a representative for all analyses.

NPs UV-VIS absorption is mainly influenced by size, shape, concentration, agglomeration capacity and the refractive index of the NP surface ${ }^{20,25}$. If NPs destabilise over time, the original absorption peak will decrease in intensity due to depletion of stable NPs. The peak is then broadened, or a secondary peak is formed at longer wavelength because of the formation of aggregates or agglomerates. Their formation also leads to changes in band position or evolution of a new SPR peak at higher wavelength ${ }^{20}$.

There was no change in the absorption maxima wavelength $\left(\lambda_{\max }\right)$ observed for the Aul sample at $540 \mathrm{~nm}$ over the 5-week experiment (Fig. 2). Intensity did not change significantly during measurement, and no NP aggregation occurred in this period. Figure 2 also enables the prediction that the colloid contains NPs with a wider distribution of particle size and shape $\mathrm{e}^{20,25}$. Table 1 presents the arithmetic mean and standard deviation of absorption intensity $(A)$ and absorbance maxima $\left(\lambda_{\max }\right)$ for the five Au NPs preparation repetitions.

The UV-VIS spectroscopy generally confirmed minor changes in absorbance and absorption maxima of the Au1-Au5 samples during the experimental period (Table 1) and the Au NPs in the colloid dispersion were stable. Moreover, no significant aggregation was observed in any prepared colloid and no visible colloid colour change occurred during storage. These results are further strengthened by the $\zeta$-potential measurements. 


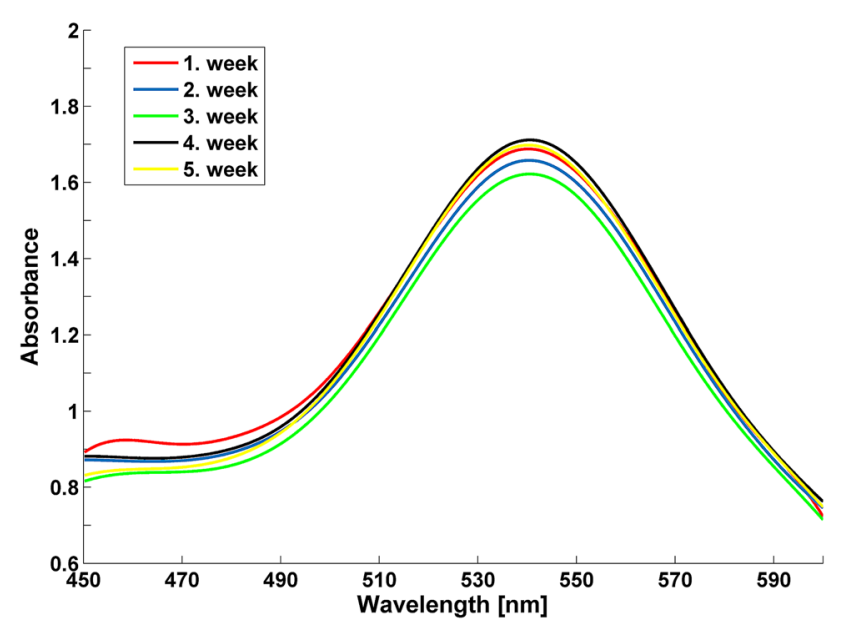

Figure 2. UV-VIS spectra of Aul sample measured over 5 weeks.

\begin{tabular}{|l|l|l|}
\hline Week & $\mathbf{A}$ & $\lambda_{\max }[\mathbf{n m}]$ \\
\hline 1 & $1.63 \pm 0.15$ & $543.40 \pm 3.13$ \\
\hline 2 & $1.60 \pm 0.12$ & $543.20 \pm 3.27$ \\
\hline 3 & $1.57 \pm 0.16$ & $542.40 \pm 3.29$ \\
\hline 4 & $1.70 \pm 0.10$ & $542.40 \pm 3.21$ \\
\hline 5 & $1.66 \pm 0.11$ & $543.20 \pm 3.27$ \\
\hline
\end{tabular}

Table 1. The arithmetic mean and standard deviation of absorption intensity (A) and absorbance maxima $\lambda_{\max }$ Au colloids prepared in parallel.

Size and morphology of phytosynthesised Au NPs. The size, morphology, and crystal structure of synthetised Au NPs were characterised by TEM. Figure 3 shows their varied shape in the illustrated Aul sample which has quasi-spherical and triangular nanoplates and hexagonal Au NPs. The Aul sample size of quasispherical NPs was $51 \pm 11 \mathrm{~nm}$, and $184 \pm 46 \mathrm{~nm}$ for triangular and hexagonal nanoplates. No significant changes in NP size were observed in these parameters within 5 weeks; with $46 \pm 14 \mathrm{~nm}$ and $180 \pm 50 \mathrm{~nm}$ observed in the 5 th week. There was also a more stabilised and less contrasting phytochemical coating around the NPs.

Statistical analysis of the Aul-5 samples established that the dominant NP shape was quasi-spherical with average $55 \pm 10 \mathrm{~nm}$ size, and the triangular and hexagonal-shaped Au NPs' size distribution was $199 \pm 55 \mathrm{~nm}$. The mean quasi-spherical and non-spherical NP sizes were evaluated 5 weeks after initial observation, with the following results; quasi-spherical NPs measured $55 \pm 12 \mathrm{~nm}$ and non-spherical NPs $194 \pm 54 \mathrm{~nm}$.

Previous UV-VIS spectra provided no evidence of different absorption peaks for smaller and larger Au NPs. This may have been due to the higher concentration of Au NPs with size around $60 \mathrm{~nm}$ which corresponds to absorption maxima of approximately $540 \mathrm{~nm}^{26}$. However, TEM characterisation confirmed the presence of NPs crystalline structure with broader particle size and shape distribution.

While our phytosynthetic method has established reproducible results, minor differences are noticeable in the observed samples. This is most likely due to the amount and content of phytochemicals in the applied plant biomass. However, further imposed conditions, such as the source of bio-reductants and bio-stabilisers, the type of metal precursor and its concentration and the contact time between biomass and precursor may enhance the reproducibility of Au NPs production with green synthesis emphasis.

In addition, the formation of Au NPs with different sizes and shapes herein was most likely associated with the wide range of biomolecules in linden bract leachate such as gallic acid, catechin and quercetin ${ }^{27,28}$. For example, the quercetin presence could be responsible for formation of spherical Au NPs in the size range from 20 to $45 \mathrm{~nm}^{16}$. Choi et al. and Gavade et al. also described the biosynthesis and stabilisation of spherical nanoparticles and triangular and hexagonal Au NPs with the size range from 17 to $80 \mathrm{~nm}$ mediated by catechin and gallic $\operatorname{acid}^{22,29}$. In addition, the linden bracts in our experiments contain the previously mentioned phytochemicals which are approved as suitable biomass for Au NP reduction and stabilisation ${ }^{30,31}$.

$\zeta$-potential measurement. The $\zeta$-potential denotes a double-layer electrostatic surface potential which is highly dependent on the immediate environment, and its value adequately determines NPs stability. The conventional theoretical boundary between NP stability and instability lies between -30 and $+30 \mathrm{mV}$; and lower and higher values than these boundaries establish colloidal stability status ${ }^{21}$. Table 2 herein highlights the established moderately stable Aul colloidal $\mathrm{pH}$ and $\zeta$-potential values. 


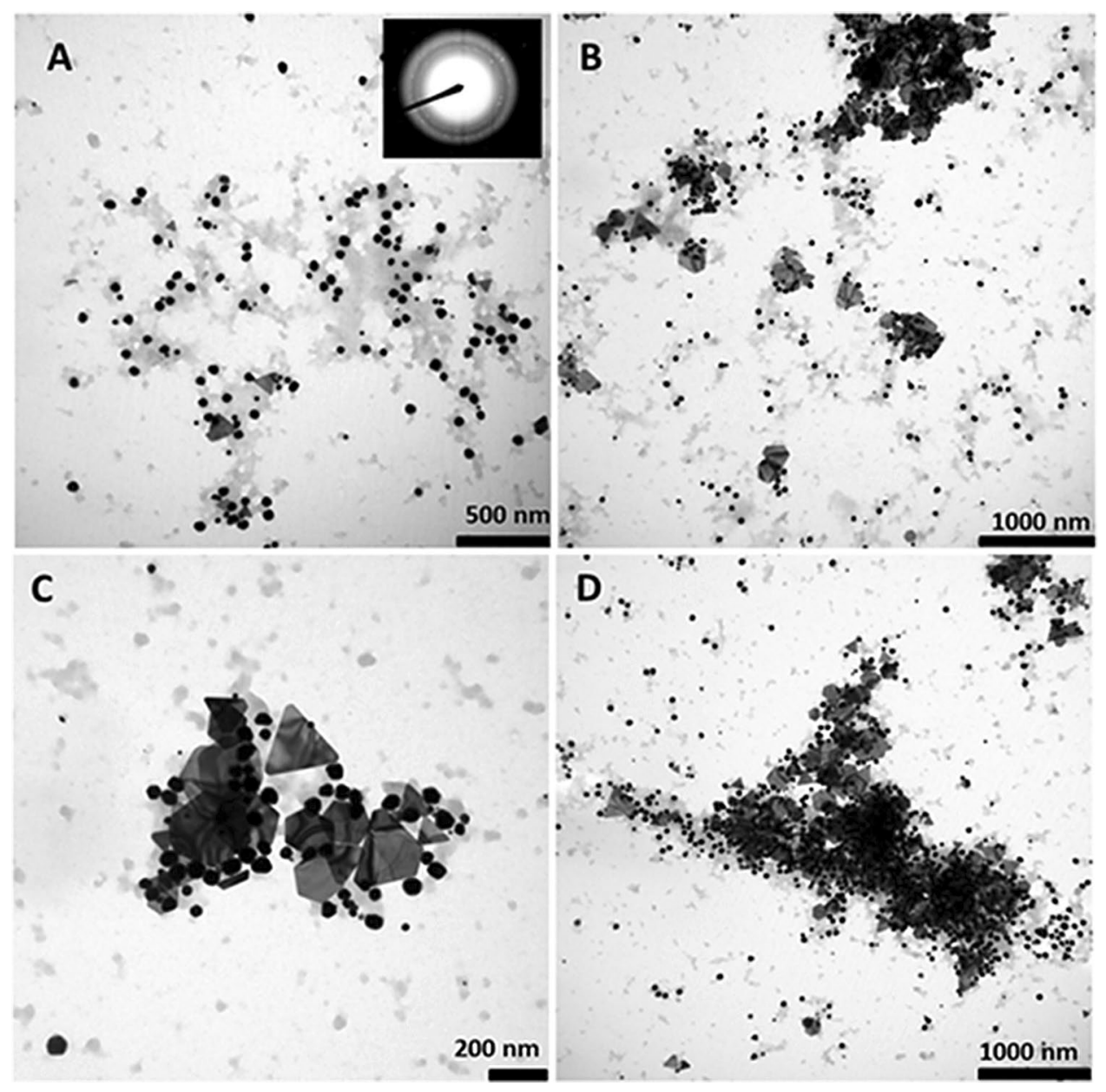

Figure 3. TEM analysis reveals phytosynthesised Au1 NPs shape and size heterogeneity. Crystalline Au NPs were confirmed by SAED. (A) The majority are quasi-spherical with some presence of triangular (B) and hexagonal (C) particles evident. Au NPs were detected both isolated and in groups (D).

\begin{tabular}{|l|l|l|}
\hline Week & $\zeta$-potential $[\mathrm{mV}]$ & $\mathbf{p H}$ \\
\hline 1 & $-24.1 \pm 0.5$ & 2.19 \\
\hline 2 & $-21.9 \pm 1.7$ & 2.15 \\
\hline 3 & $-20.8 \pm 0.6$ & 1.77 \\
\hline 4 & $-20.2 \pm 1.4$ & 2.03 \\
\hline 5 & $-19.9 \pm 1.4$ & 2.01 \\
\hline
\end{tabular}

Table 2. $\zeta$-potential and $\mathrm{pH}$ values of Aul samples over the five-week experimental period.

The $\zeta$-potential was regularly measured for all samples, and Fig. 4 shows the slight alteration in $\zeta$-potential arithmetic mean over the experimental period. The phytosynthesised Au NPs were classified as moderately stable because the measured values did not reach the estimated stability boundary. The negative $\zeta$-potential values were detected here because the capping agents comprised active bioorganic compounds with long-term change effects ${ }^{32}$. We then considered the stabilisation process complete because no significant change was noted in $\zeta$-potential value.

The Au NPs samples' pH value was continuously monitored because the $\zeta$-potential value fundamentally depends on $\mathrm{pH}$ and temperature change. Figure 5 herein shows that the $\mathrm{pH}$ of all $\mathrm{Au}$ NPs samples was constant throughout the experimental period at approximately $\mathrm{pH} 2$ at constant laboratory temperature.

Soman degradation. Hydrolytic degradation of soman was performed in the presence of three materials: (i) pure linden bracts leachate (C1); (ii) $\mathrm{HAuCl}_{4} \mathrm{Au}$ precursor and (iii) colloidal Au NPs (Au1). 


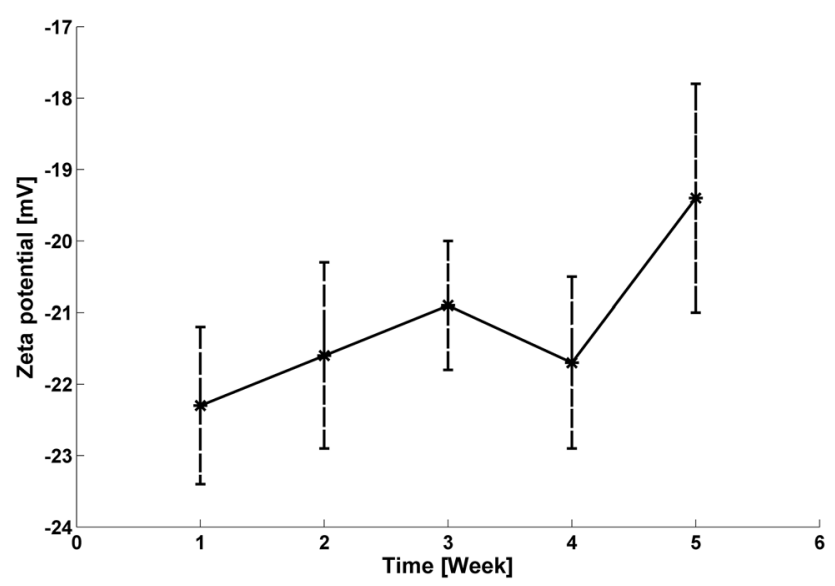

Figure 4. Arithmetic mean and standard deviation of $\zeta$-potential values for the measured samples, including Aul.

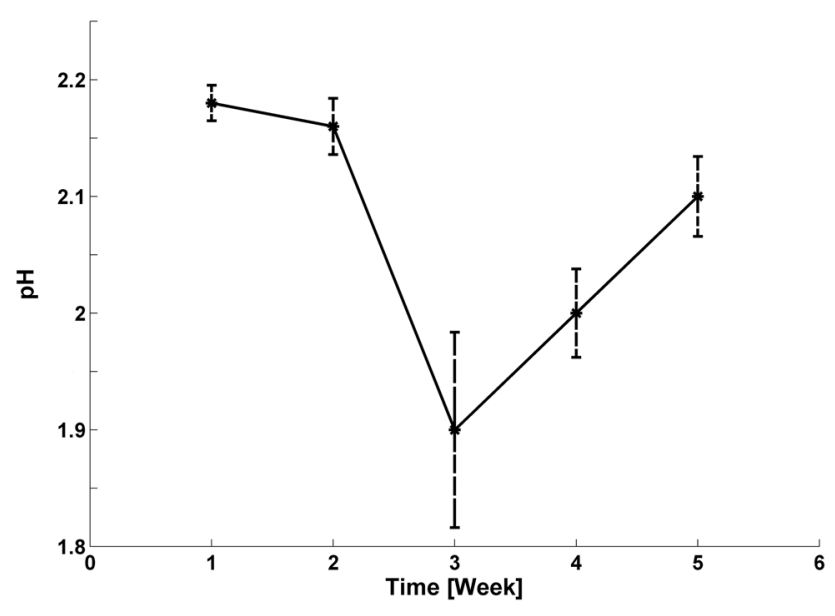

Figure 5. Arithmetic mean and standard deviation of $\mathrm{pH}$ values for measured samples including Aul.

Figure 6 shows the hydrolysis course catalysed by colloidal Au NPs with $2.5 \mathrm{mmol} \mathrm{dm}^{-3} \mathrm{Au}$ compared to soman degradation with Au precursor containing the same Au concentration and the $\mathrm{Cl}$ control sample. The Au NPs achieved $99.38 \%$ soman conversion in $24 \mathrm{~h}$ with $0.2156 \mathrm{~h}^{-1}$ degradation rate constant, and the phytosynthesised Au NPs can influence soman hydrolysis through the quantum-size effects generated by electrons confined in a small volume. The literature states that a basic environment of $\mathrm{pH} 8-14$ shifts the reaction equilibrium to degradation products. However, the Au NP catalytic effect has been confirmed in the $\mathrm{pH} 2.2$ acidic environment, and this is much better than literature reports of hydrolysis proceeding at neutral $\mathrm{pH}^{5}$.

The resultant conversion of soman in the presence of the $\mathrm{pH} 4 \mathrm{Au}$ precursor was $97.77 \%$ after $24 \mathrm{~h}$ with attendant reaction rate constant of $0.1614 \mathrm{~h}^{-1}$. The differing $\mathrm{Au}(\mathrm{I})$ and $\mathrm{Au}(\mathrm{III})$ ) oxidation states participate as catalysts in organic synthesis. For example, the $\mathrm{HAuCl}_{4} \mathrm{Au}$ precursor used as a catalyst degraded soman due to its oxidation potential ${ }^{33}$.

Although the $\mathrm{pH} 5.1$ linden leachate exhibited no degradation effect on the soman nerve agent and the phytochemicals in the water extract did not influence soman decomposition, soman conversion by linden leachate proceeded in a similar manner to the simple soman hydrolysis ${ }^{5}$.

The degradation products were determined by SPME and GC/MS screening analysis. The amount of MPA standard solution, as the final degradation product, was $100 \mathrm{ng}$, and Table 3 highlights identification of the following compounds by mass spectra: ethylacetate (Et-Ac, CAS: 141-78-6), pinacolylalcohol (P-ol, CAS: 464-07-3), dipinacolylmethyl phosphonate (DPMP, CAS: 7040-58-6), soman (CAS: 96-64-0).

The following were also present in the mass spectrum (1) Si-pinacolylmethylphosphonic acid PMPA-the Si derivative formed after hydrolysis of the P-F bond and (2) Si-methyl phosphonic acid MPA-the Si derivative formed after hydrolysis of the P-F and P-O bonds. Figure 7 shows that PMPA was the product most formed in the first stage of the samples' soman hydrolysis, and Table 4 depicts that MPA was detected as a final non-toxic degradation product ${ }^{34,35}$.

Soman hydrolysis was catalysed more effectively with $\mathrm{Au}$ NPs than with $\mathrm{HAuCl}_{4} \mathrm{Au}(\mathrm{III})$ ions. The soman degradation mechanism was most likely different in the presence of $\mathrm{Au}(\mathrm{III})$ ions to the $\mathrm{Au}$ NPs action. We 


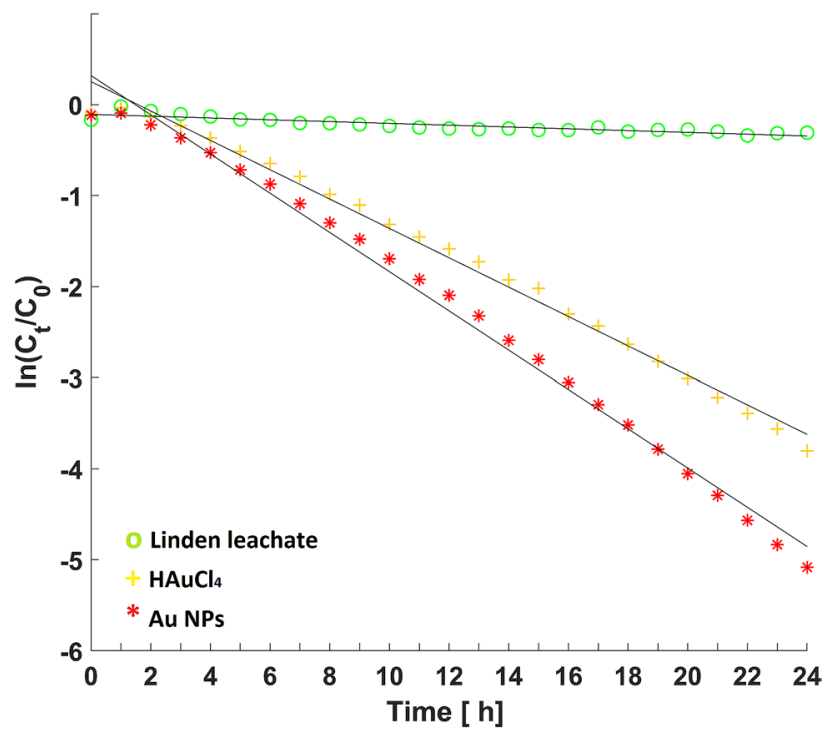

Figure 6. Kinetic degradation of soman hydrolysis in the presence of linden leachate, gold precursor and $\mathrm{Au}$ NPs.

\begin{tabular}{|l|l|l|l|l|}
\hline \multirow{2}{*}{ Samples } & \multicolumn{4}{|l|}{ Monitored analytes (Peak area) } \\
\cline { 2 - 5 } & Et-Ac & P-ol & DPMP & Soman \\
\hline Linden leachate & - & 688,457 & $1,345,668$ & $38,689,503$ \\
\hline $\mathrm{HAuCl}_{4}\left(2.5 \mathrm{mmol} \cdot \mathrm{dm}^{-3}\right)$ & 847,594 & $1,719,116$ & $5,953,960$ & $1,297,049$ \\
\hline $\mathrm{Au} \mathrm{NPs}\left(2.5 \mathrm{mmol} \cdot \mathrm{dm}^{-3}\right)$ & - & $1,995,211$ & $1,043,776$ & 336,166 \\
\hline
\end{tabular}

Table 3. SPME monitoring of hydrolysis products after $24 \mathrm{~h}$.

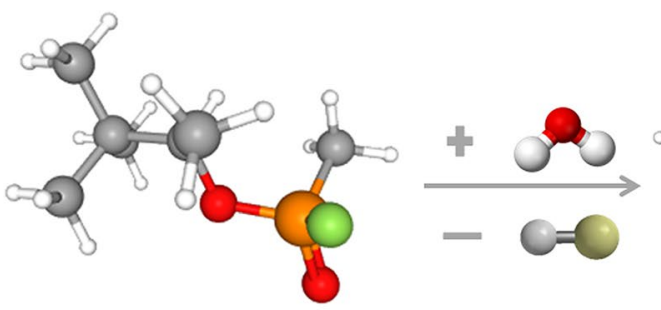

Soman

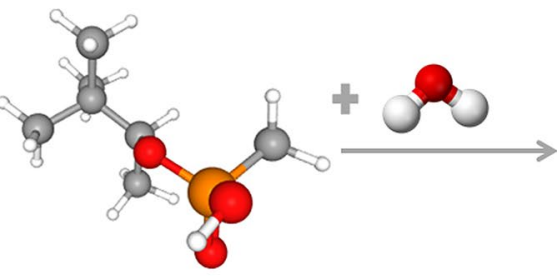

PMPA

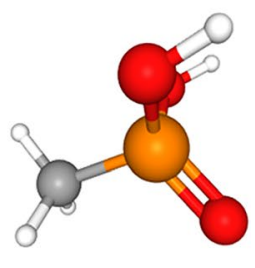

MPA

Figure 7. Hydrolysis of $\operatorname{soman}^{34,35}$.

\begin{tabular}{|l|l|l|l|}
\hline \multirow{2}{*}{ Samples } & \multicolumn{3}{|l|}{ Monitored analytes (Peak area) } \\
\cline { 2 - 5 } & Soman & PMPA-Si & MPA-Si \\
\hline Standard solution of soman $(100 \mathrm{ng})$ & $11,391,354$ & - & - \\
\hline Standard solution of MPA-Si $(100 \mathrm{ng})$ & - & - & $44,622,216$ \\
\hline Linden leachate & $35,872,335$ & 738,678 & 745,057 \\
\hline $\mathrm{HAuCl}_{4}\left(2.5 \mathrm{mmol} \cdot \mathrm{dm}^{-3}\right)$ & - & $1,874,961$ & 134,487 \\
\hline $\mathrm{Au} \mathrm{NPs}^{2}\left(2.5 \mathrm{mmol} \cdot \mathrm{dm}^{-3}\right)$ & - & $23,369,827$ & 501,546 \\
\hline
\end{tabular}

Table 4. Products of soman degradation after $24 \mathrm{~h}$ detected by GC/MS screening analyses. 
observed that ethyl acetate and the highest concentration of DPMP were detected in the sample only when $\mathrm{HAuCl}_{4}$ was present, because the PMPA-OH group was then preferentially esterified to form DPMP. Therefore, the concentration of the low-molecular PMPA and MPA final products in the Au NPs' sample was 12.5 and 3.7 times higher, respectively, than in the reaction where $\mathrm{HAuCl}_{4}$ was mixed with soman.

Finally, although samples with nanogold had lower $\mathrm{pH}$ value, the Au NPs provided better catalytic activity for soman hydrolysis than $\mathrm{HAuCl}_{4}$ after $24 \mathrm{~h}$. In addition, toxicology studies record that pinacolylmethylphosphonic acid is formed as an intermediate and methylphosphonic acid is usually formed as a final degradation product of soman hydrolysis and is considered non-toxic ${ }^{2}$.

\section{Methods}

Au nanoparticle phytosynthesis. Tilia sp. bracts were collected in the Nová Ves area of Frýdlant nad Ostravicí in The Czech Republic. Here, $2 \mathrm{~g}$ of the dried biomass and $50 \mathrm{~mL}$ of $80^{\circ} \mathrm{C}$ Milli-Q water were mixed for $15 \mathrm{~min}$ at static condition. The leachate was filtered through a $0.22 \mu \mathrm{m}$ syringe filter (MCE, Millex-GS, Merck Millipore, Germany) and $5 \mathrm{mmol} \cdot \mathrm{dm}^{-3}$ aqueous solution of $\mathrm{HAuCl}_{4}$ (Sigma-Aldrich, USA) was used as initial precursor for AuNP generation. The leachate and precursor were mixed in 1:1 v/v ratio for $15 \mathrm{~min}$ and the final colloid was maintained in the dark at $5^{\circ} \mathrm{C}$.

The $\mathrm{Au}$ NPs and linden bracts leachates preparations were repeated five times to control phytosynthetic reproducibility. The final AuNP samples were denoted Au1, Au2, Au3, Au4 and Au5, and the C1, C2, C3, C4 and $\mathrm{C} 5$ linden bracts leachates of each sample were stored as controls. Finally, the colloidal solutions were brought to $25^{\circ} \mathrm{C}$ for subsequent experiments and measurements.

Physical-chemical properties of colloidal Au nanoparticles. Study of Au colloidal stability and phytosynthetic reproducibility. Au NP stability and phytosynthesis reproducibility were studied by regularly measuring UV-VIS absorption maxima, $\zeta$-potential and colloid $\mathrm{pH}$ values each week for 5 weeks for all Au1-Au5 samples. The characteristic Au NPs absorption peaks were measured by UV-VIS spectrophotometer (LAMBDA 11, Perkin Elmer Instruments, USA) with $0.5 \mathrm{~nm}$ unit step in the $450-600 \mathrm{~nm}$ wavelength range. The $\zeta$-potential was periodically controlled by ZetaSizer Nano-ZS (ZEN 3600; Malvern Instruments Ltd., UK), and solutions were evaluated on system acid-base equilibrium by measuring $\mathrm{pH}$ values by EUTECH $\mathrm{pH} 5+$ meter (Eutech Instruments, USA).

NPs size distribution, morphology and crystal structure determination. NP morphology and size distribution were characterised by transmission electron microscopy (TEM) at $80 \mathrm{kV}$ using JEOL $1200 \mathrm{EX}$ (JEOL, Japan), and the crystal structure was monitored by selected area electron diffraction (SAED). The $2 \mu \mathrm{L}$ liquid sample was placed on a copper grid coated with carbon and dried under laboratory conditions, and the NPs size distribution was evaluated by JMicroVision programme with approximately 150 NPs analysed per sample. (www.jmicrovisi on.com).

Soman degradation. The soman degradation experiments were performed at the National Institute for Nuclear, Biological and Chemical Protection at Kamenná in The Czech Republic. The GC-MS system (GC7890A/ MSD5975 C, inert XL, Agilent Technologies, USA) equipped with automatic solid phase micro-extraction (CTC PAL, Thermo Scientific, USA) and HP-5MS silica column $(30 \mathrm{~m} \times 0.25 \mathrm{~mm} \times 0.25 \mu \mathrm{m}$ film thickness $)$ monitored soman degradation. Solid phase micro-extraction (SPME) device with 65-micron polydimethylsiloxane/ divinylbenzene (PDMS/DVB) Stableflex Supelco fibre was utilised for soman transfer and injection into the $\mathrm{GC}$ injection port. Both sorption and consequent desorption time was $300 \mathrm{~s}$ in both cases at $30^{\circ} \mathrm{C}$ and $250{ }^{\circ} \mathrm{C}$, respectively. Agitation at $500 \mathrm{rpm}$ for $180 \mathrm{~s}$ then homogenised the sample with the following GC temperature program was as follows: $45^{\circ} \mathrm{C}(1 \mathrm{~min}), 15^{\circ} \mathrm{C} / \mathrm{min}, 80^{\circ} \mathrm{C}(1 \mathrm{~min}), 25^{\circ} \mathrm{C} / \mathrm{min}$ up to $280^{\circ} \mathrm{C}(5 \mathrm{~min})$. The $99.9 \%$

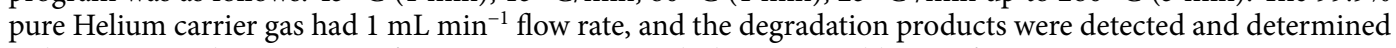
utilising MSD ChemStation software E.02.02.1431 with the NIST 08 library of mass spectra.

Three different samples were tested for soman degradation. Their injections into the GC column was performed at hourly intervals for $24 \mathrm{~h}$ as follows: $5 \mu \mathrm{l}$ of soman (purity $>95 \%$, concentration in the resulting solution was $341 \mu \mathrm{g} \mathrm{cm}^{-3}$ ) was mixed with $15 \mathrm{ml}$ of (i) linden leachate $\mathrm{C} 1$ as the control experiment, (ii) $\mathrm{HAuCl}_{4}$ precursor $\left(2.5 \mathrm{mmol} \mathrm{dm}{ }^{-3}\right.$ of $\left.\mathrm{Au}\right)$ and (iii) Aul an aqueous solution of linden leachate containing Au NPs $\left(2.5 \mathrm{mmol} \mathrm{dm}^{-3}\right.$ of $\mathrm{Au}$ ). Residual concentrations of soman after degradation monitored for $24 \mathrm{~h}$ were fitted using pseudo-first order kinetics and the rate constant $(k)$ was calculated by Eq. (1):

$$
\ln \left(c_{t} / c_{0}\right)=-k \mathrm{t}
$$

where $\mathrm{c}$ and $\mathrm{c}_{0}$ describe the percentage content of soman at given time $t$ and time zero, respectively, and $t$ is reaction time (h). Soman conversion was then calculated by Eq. (2).

$$
X_{\text {soman }}=\mathrm{c}_{0}-\mathrm{c}_{\mathrm{t}}
$$

where $X_{\text {soman }}$ is the percentage of soman conversion and $c_{\mathrm{t}}$ percentage is the content of soman in time $t$. The degradation of soman using sample Aul was repeated two times.

Analysis of degradation products. Decreased soman concentration over time was observed in the samples described above. All three samples were individually extracted after 24 -h soman degradation into $2 \times 3 \mathrm{~mL}$ $\mathrm{CH}_{2} \mathrm{Cl}_{2} / \mathrm{MeOH}$ (9:1) for determination of formed degradation products. The organic extracts were dried by $\mathrm{Na}_{2} \mathrm{SO}_{4}$ and $1 \mathrm{~mL}$ aliquots of each extracts were derivatised by adding $25 \mu \mathrm{L}$ of BSTFA derivative agent (N,O-Bis 
(trimethylsilyl) trifluoroacetamide). The reaction mixture was shaken by hand and this was followed by derivatisation for $2 \mathrm{~h}$ at $40-50^{\circ} \mathrm{C}$. Finally, $1 \mu \mathrm{L}$ was taken from each reaction mixture for GC/MS screening analysis and mass spectra were evaluated by NIST08 database.

Statistical analysis. All graphs were created in MATLAB software (MathWorks, USA). The arithmetic mean and standard deviation of UV-VIS data, NPs size, $\zeta$-potential and the $\mathrm{pH}$ values of Au1-Au5 colloids were processed by standard formulae in MATLAB software (MathWorks, USA).

\section{Conclusions}

Colloidal nanoparticle properties ensure that they are very promising catalytic agents. However, in addition to the necessity that NPs preparation methods and techniques are both economically and environmentally sustainable, increasing attention in industrial chemistry now focuses on 'green chemistry' where synthesis is inspired by processes closer to nature. Therefore, our Au NPs were prepared and stabilised by eco-friendly phytosynthesis.

Linden bracts water leachate was used as the reducing and capping agent, and the preparation of Au NPs was repeated five times to control phytosynthesis reproducibility. Here, the phytosynthesised Au colloid $\zeta$-potential values moved around.

$-20 \mathrm{mV}$ with approximately $540 \mathrm{~nm}$ Au NP absorption maxima. The average Au NP sizes were $55 \pm 10 \mathrm{~nm}$ for quasi-spherical NPs and $199 \pm 55 \mathrm{~nm}$ for polygonals. Importantly, the phytosynthesised NPs preparation method was proven reproducible, and acceptable colloid was confirmed in the 5-week period.

In addition, the phytosynthesised Au NPs' catalytic activity was established by soman degradation within $24 \mathrm{~h}$. While it was interesting to note that the $\mathrm{HAuCl}_{4} \mathrm{Au} \mathrm{NPs}$ precursor also proved able to degrade soman, the Au NPs provided much better catalytic activity. This was due to the previously mentioned peak area of the PMPA and MPA low-molecular final products in the sample, with the Au NPs being 12.5 and 3.7 times higher, respectively, than soman degradation induced solely by $\mathrm{HAuCl}_{4}$.

In conclusion, this research confirmed the high potential of bio-nanotechnology for reproducible preparation of stable and functional nanocatalysts for degradation of hazardous substances, and most importantly, these catalytically active nanomaterials can be prepared by green biotechnology.

Received: 22 September 2020; Accepted: 3 February 2021

Published online: 18 February 2021

\section{References}

1. Kim, K., Tsay, O. G., Atwood, D. A. \& Churchill, D. G. Destruction and detection of chemical warfare agents. Chem. Rev. 111, 5345-5403 (2011).

2. Plachá, D. et al. Adsorption of nerve agent simulants onto vermiculite structure: experiments and modelling. J. Hazard. Mater. 382, 121001 (2020).

3. Štengl, V. et al. Zirconium doped nano-dispersed oxides of $\mathrm{Fe}, \mathrm{Al}$ and $\mathrm{Zn}$ for destruction of warfare agents. Mater. Charact. 61, 1080-1088 (2010).

4. Alvaro, M. et al. Visible-light photocatalytic activity of gold nanoparticles supported on template-synthesized mesoporous titania for the decontamination of the chemical warfare agent Soman. Appl. Catal. B 99, 191-197 (2010).

5. Holišová, V. et al. Biosilica-nanogold composite: Easy-to-prepare catalyst for soman degradation. Arab. J. Chem. 12, 262-271 (2019).

6. Liu, X. Y., Wang, A., Zhang, T. \& Mou, C. Y. Catalysis by gold: New insights into the support effect. Nano Today 8, 403-416 (2013).

7. Grisel, R., Weststrate, K. J., Gluhoi, A. \& Nieuwenhuys, B. E. Catalysis by gold nanoparticles. Gold Bull. 35, 39-45 (2002).

8. Holišová, V. et al. Magnetically modified nanogold-biosilica composite as an effective catalyst for CO oxidation. Arab. J. Chem. 12, 1148-1158 (2018).

9. Sarina, H. S., Eric, R. \& Zhu, W. Photocatalysis on supported gold and silver nanoparticles under ul- traviolet and visible light irradiation. Green Chem. 15, 1814-1833 (2013).

10. Bommavaram, M., Korivi, M., Borelli, D. P. R., Pabbadhi, J. D. \& Nannepaga, J. S. Bacopa monniera stabilized gold nanoparticles (BmGNPs) alleviated the oxidative stress induced by aluminum in albino mice. Drug Inven. Today 5, 113-118 (2013).

11. Kratošová, G. et al. From biotechnology principles to functional and low-cost metallic bionanocatalysts. Biotechnol. Adv. 37, 154-176 (2019).

12. He, S. et al. Biosynthesis of gold nanoparticles using the bacteria Rhodopseudomonas capsulata. Mater. Lett. 61, 3984-3987 (2007).

13. Brayner, R. et al. Cyanobacteria as bioreactors for the synthesis of Au, Ag, Pd, and Pt nanoparticles via an enzyme-mediated route. J. Nanosci. Nanotechnol. 7, 2696-2708 (2007).

14. Ullah, S. et al. Bio-fabrication of catalytic platinum nanoparticles and their in vitro efficacy againts lungs cancer cell lines (A549). J. Photochem. Photobiol., B 173, 368-375 (2017).

15. Irfan, M., Ahmad, T., Moniruzzaman, M. M., Abdullah, B. B. \& Bhattacharjee, S. Ionic liquid mediated biosynthesis of gold nanoparticles using elaeis guineensis (oil palm) leaves extract. Proc. Eng. 148, 568-572 (2016).

16. Das, D. K., Chakraborty, A., Bhattacharjee, S. \& Dey, S. Biosynthesis of stabilised gold nanoparticle using an aglycone flavonoid, quercetin. J. Exp. Nanosci. 8, 649-655 (2013).

17. Mittal, A. K., Chisti, Y. \& Banerjee, U. C. Synthesis of metallic nanoparticles using plant extracts. Biotechnol. Adv. 31, 346-356 (2013).

18. Lai, X. et al. Rapid microwave-assisted bio-synthesized silver/Dandelion catalyst with superior catalytic performance for dyes degradation. J. Hazard. Mater. 371, 506-512 (2019).

19. Konvickova, Z. et al. Phytosynthesis of colloidal $\mathrm{Ag}-\mathrm{AgCl}$ nanoparticles mediated by Tilia sp. leachate, evaluation of their behaviour in liquid phase and catalytic properties. Colloid Polym. Sci. 296, 677-687 (2018).

20. Irfan, M., Ahmad, T., Moniruzzaman, M., Bhattacharjee, S. \& Abdullah, B. Size and stability modulation of ionic liquid functionalized gold nanoparticles synthesized using Elaeis guineensis (oil palm) kernel extract. Arab. J. Chem. 13, 75-85 (2017).

21. Bhattacharjee, S. DLS and zeta potential: what they are and what they are not?. J. Control. Release 235, 337-351 (2016).

22. Choi, Y. et al. Catechin-capped gold nanoparticles: green synthesis, characterization, and catalytic activity toward 4-nitrophenol reduction. Nanoscale Res. Lett. 9, 103 (2014).

23. Gavade, N. L., Kadam, A. N., Suwarnkar, M. B., Ghodake, V. P. \& Garadkar, K. M. Biogenic synthesis of multi-applicative silver nanoparticles by using Ziziphus Jujuba leaf extract. Spectrochim. Acta A Mol. Biomol. Spectrosc. 136, 953-960 (2015). 
24. Sheny, D. S., Mathew, J. \& Philip, D. Synthesis characterization and catalytic action of hexagonal gold nanoparticles using essential oils extracted from Anacardium occidentale. Spectrochim. Acta A Mol. Biomol. Spectrosc. 97, 306-310 (2012).

25. Amendola, V. \& Meneghetti, M. Size evaluation of gold nanoparticles by UV-vis spectroscopy. J. Phys. Chem. C 113, 4277-4285 (2009).

26. Nanocomposix - Gold Nanoparticles: Optical Properties. (2020). https://nanocomposix.com/pages/gold-nanoparticles-opticalproperties.

27. Cittan, M., Altuntaş, E. \& Çelik, A. Evaluation of antioxidant capacities and phenolic profiles in Tilia cordata fruit extracts: a comparative study to determine the efficiency of traditional hot water infusion method. Ind. Crops Prod. 122, 553-558 (2018).

28. Barreiro Arcos, M. L. et al. Tilia cordata Mill. Extracts and scopoletin (isolated compound): differential cell growth effects on lymphocytes. Phytother. Res. PTR 20, 34-40 (2006).

29. Wang, W. et al. One-step synthesis of biocompatible gold nanoparticles using gallic acid in the presence of poly-(N-vinyl-2-pyrrolidone). Colloids Surf. A 301, 73-79 (2007).

30. Karioti, A. et al. HPLC-DAD and HPLC-ESI-MS analyses of Tiliae flos and its preparations. J. Pharmac. Biomed. Anal. 100, 205-214 (2014).

31. Oniszczuk, A. \& Podgórski, R. Influence of different extraction methods on the quantification of selected flavonoids and phenolic acids from Tilia cordata inflorescence. Ind. Crops Prod. 76, 509-514 (2015).

32. Holišová, V. et al. Phytosynthesis of $\mathrm{Au}$ and $\mathrm{Au} / \mathrm{ZrO}_{2}$ bi-phasic system nanoparticles with evaluation of their colloidal stability. J. Nanosci. Nanotechnol. 19, 2807-2813 (2019).

33. Hashmi, A. S. K. Gold-catalyzed organic reactions. Top. Organomet. Chem. 44, 143-164 (2013).

34. Seto, Y., Tachikawa, M., Kanamori-kataoka, M., Sasamoto, K. \& Ochiai, N. Target analysis of tert-butyldimethylsilyl derivatives of nerve agent hydrolysis products by selectable one-dimensional or two-dimensional gas chromatography-mass spectrometry. J. Chromatogr. A 1501, 99-106 (2017).

35. Vellingiri, K., Philip, L. \& Kim, K. Metal-organic frameworks as media for the catalytic degradation of chemical warfare agents. Coord. Chem. Rev. 353, 159-179 (2017).

\section{Acknowledgements}

We thank Jay Davis and Ray J. Marshall for language review. This work was kindly supported by SGS SP2019/23, SP2020/70 and SP2020/74. Further, the work was supported by the Ministry of Education of the Czech Republic in Scientific, Grant Agency of the Ministry of Education, Science, Research and Sports of the Slovak Republic and the Slovak Academy of Sciences via Grants VEGA 1/0164/17, VEGA 1/0146/18, KEGA 013SPU-4/2019 and the Grant Numbered CZ.02.1.01/0.0/0.0/16_019/0000753 under OP RDE.

\section{Author contributions}

V.H. prepared Au nanoparticles, was responsible for UV-VIS and $\mathrm{pH}$ analysis, managed experimental section, processed measured data and wrote the main manuscript text. M.U. and D.P. focused on the GC analysis of soman degradation and their interpretation, P.M. guided $\zeta$-potential, G.K., V.H. and Z.K. focused on the interpretation of the TEM analysis. All authors reviewed the manuscript.

\section{Competing interests}

The authors declare no competing interests.

\section{Additional information}

Correspondence and requests for materials should be addressed to V.H. or D.P.

Reprints and permissions information is available at www.nature.com/reprints.

Publisher's note Springer Nature remains neutral with regard to jurisdictional claims in published maps and institutional affiliations.

(c) (i) Open Access This article is licensed under a Creative Commons Attribution 4.0 International License, which permits use, sharing, adaptation, distribution and reproduction in any medium or format, as long as you give appropriate credit to the original author(s) and the source, provide a link to the Creative Commons licence, and indicate if changes were made. The images or other third party material in this article are included in the article's Creative Commons licence, unless indicated otherwise in a credit line to the material. If material is not included in the article's Creative Commons licence and your intended use is not permitted by statutory regulation or exceeds the permitted use, you will need to obtain permission directly from the copyright holder. To view a copy of this licence, visit http://creativecommons.org/licenses/by/4.0/.

(c) The Author(s) 2021 